\title{
A carrier's perspective on container network configuration at sea and on land
}

\author{
Theo E. Notteboom*
}

\begin{abstract}
This paper deals with network configurations in liner shipping and inland transportation from a carrier's perspective. The cost efficiency of different possible network configurations in the foreland-hinterland continuum is discussed based on a cost model and on a qualitative analysis. It is demonstrated that the tendency towards cargo concentration in a limited number of ports has led to the redesign of collection and distribution networks in the hinterland. Further cargo bundling in the foreland-hinterland continuum towards even fewer ports and inland centres is only interesting from a cost perspective if considerable economies of scale and density can be realised in the associated hinterland networks. The more cost efficient the network becomes, the less convenient that network could be for the shippers' needs in terms of frequency and flexibility. As such, the future configuration of liner shipping networks and inland transport networks will largely depend on the balance of power between carriers and shippers.
\end{abstract}

Keywords: Containerisation, Liner Shipping, Hinterland Transport, Network Configuration

\section{INTRODUCTION}

Containerisation, intermodality and the associated logistics have led to a timespace convergence and have induced spatial and functional adaptations to port systems and hinterland networks. In the past, shipping networks and inland networks developed somewhat independently from each other. Logistics integration and advanced network-based bundling systems however have led to increased interaction between the sea and the landside. Shipping lines' keen interest in hinterland networks and inland logistics provides some evidence of the increased integration of sea and landside operations.

This paper deals with the configuration of liner shipping networks and hinterland networks from a carrier's perspective. The research questions addressed in this paper are:

- What factors affect the design of deepsea liner services and hinterland services?

\footnotetext{
'Port Economist, Institute of Transport and Maritime Management Antwerp (ITMMA), University of Antwerp, Keizerstraat 64, 2000 Antwerp (Belgium), Tel: +32 3 275.51.49, fax: +32 3 275.51.50, E-mail: theo.notteboom@ua.ac.be Website: www.itmma.com
} 
- Is there a causal relation between liner service network design and inland service network configuration?

- What is the impact of inland transport costs and potential economies of scale in inland transport on the optimal design of a liner service network?

Answers to these questions will be formulated based on cost model results and on a qualitative analysis.

\section{THE INLAND FOCUS OF SHIPPING LINES}

Much literature has addressed the involvement of container shipping lines in inland transport and port operations (see e.g. Konings, 1993, Baird \& Lindsay, 1996, Graham, 1998, Cariou, 2001 and Heaver, 2002). The demand pull force of the market and the push for a broader revenue base are some of the main driving forces for carriers to integrate their services along the foreland-hinterland continuum. Carriers have to meet shippers' requirements in terms of frequency, punctuality, reliability and geographical coverage (Slack et al, 1996). The potential cost saving in door-to-door transport is another aspect that deserves special attention. In some cases shipping lines end up by managing the container terminal operation and inland transport as they require improvements in terminal effectiveness and landside operations not only to lower the cost burden of door-to-door transport, but also to make sure that the savings at sea with post-panamax vessels are not to be lost on land.

Much literature has suggested that economies of scale can be achieved through scale increases in vessel size. Larger ships generally have a lower cost per TEU-mile than smaller units with the same load factor (Drewry, 2001, Cullinane et al, 1999, Waals and Wijnolst, 2001). The recent scale enlargement in vessel size has reduced the slot costs in container trades, but carriers have not reaped the full benefits of economies of scale at sea (Lim, 1998). Poorer slot utilization and the need to go out and buy more cargo at lower rates can have a profound impact on carriers' revenues and lead to lower profitability. In a shipping industry already dominated by large vessels, mergers/acquisitions and strategic alliances the potential cost savings at sea still left are getting smaller and the pressure to find cost savings elsewhere is growing.

Carriers have identified inland logistics as one of the most vital area still left to cut costs. More economical ships and alliance co-operation have lowered ship system costs, but at the same time intermodal costs share an increasing part of the total cost. Figure 1 provides realistic examples of the impact of route length, vessel size and inland costs (excluding ship terminal costs) on the portion of terminal and inland costs in total door-to-door container costs. Three route lengths have been considered. A round trip of 17000 nautical miles is comparable to trans-Pacific liner services, the $24000 \mathrm{~nm}$ route is typical of the

Europe-Far East trade and the $8000 \mathrm{~nm}$ round trip is common on the trans-Atlantic route. Calculations are based on a cost model of which the cost components are listed in appendix. Data are collected on variables such as bunker consumption, bunker prices, capital costs, daily running costs, container costs, port dues (sum of towage dues, pilotage dues, traffic control system dues, reporting dues, (un)mooring dues, 
berth dues and tonnage dues), administrative costs, etc. The cost model builds on earlier conceptual work from a.o. Cullinane et al (1999), Baird (2001) and Stopford (1999). Cullinane et al (1999) have modelled the trade-off between economies of ship size and diseconomies of scale in ports. Their analysis only included those costs which are a function of ship size. The model presented here is extended to include all door-to-door costs to the carrier, including costs which are unrelated to vessel size. The cost model will be reused in later sections of this paper. There are several assumptions made here which have to be taken into account and which simplify the example to some extent. For instance, it is assumed here that the terminal handling costs per box do not alter with vessel size or route length. The limited fine-tuning and differentiation in the operational cost components are not expected to have a serious impact on the final outcomes. The terminal and inland costs as depicted on the vertical axis of figure 1 include terminal handling costs, inland transport costs on the route origin/port of loading and the route port of discharge/final destination (including terminal costs for the inland transport modes), inter-zone repositioning of empty containers and cargo claims.

Figure 1. The impact of route length, vessel size and inland transport costs on the share of landside costs in door-to-door cost per TEU

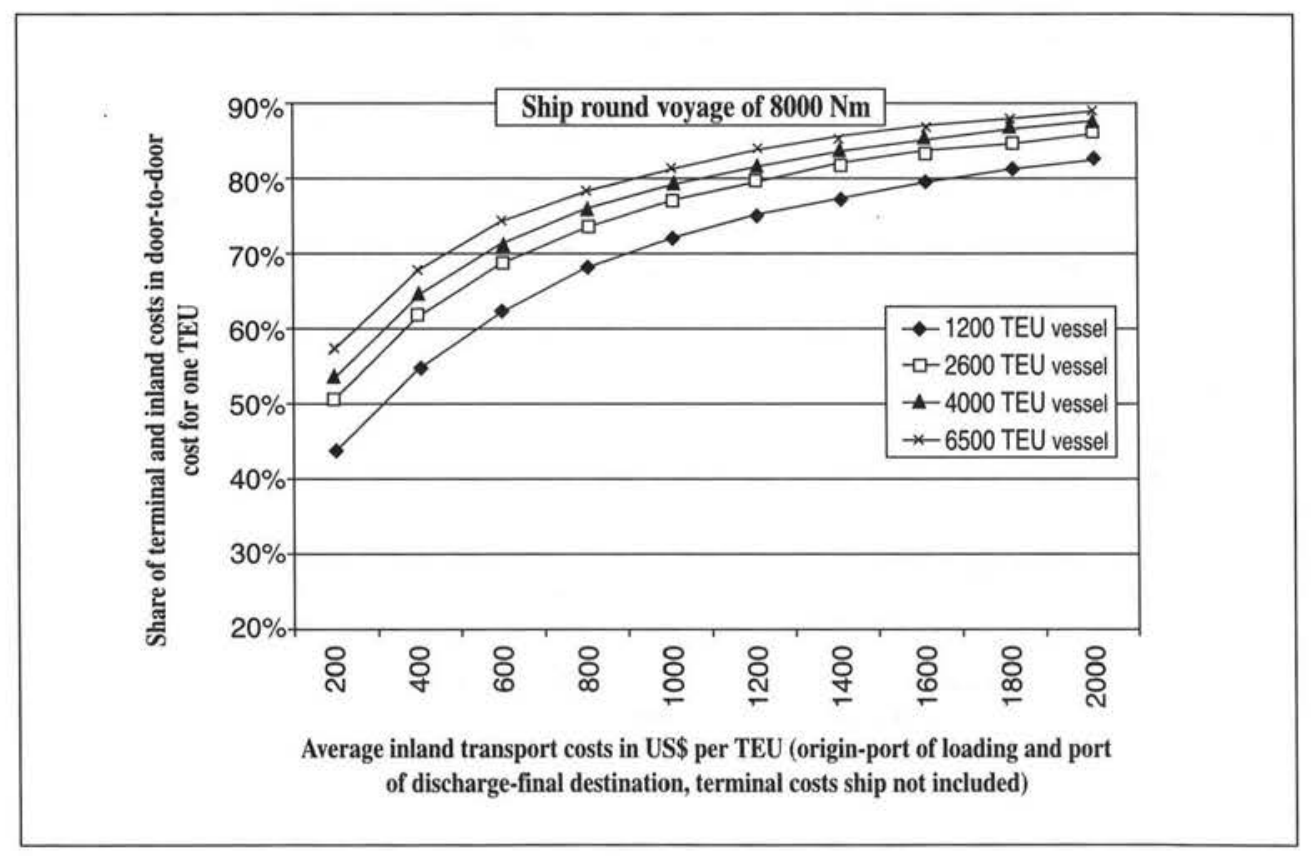




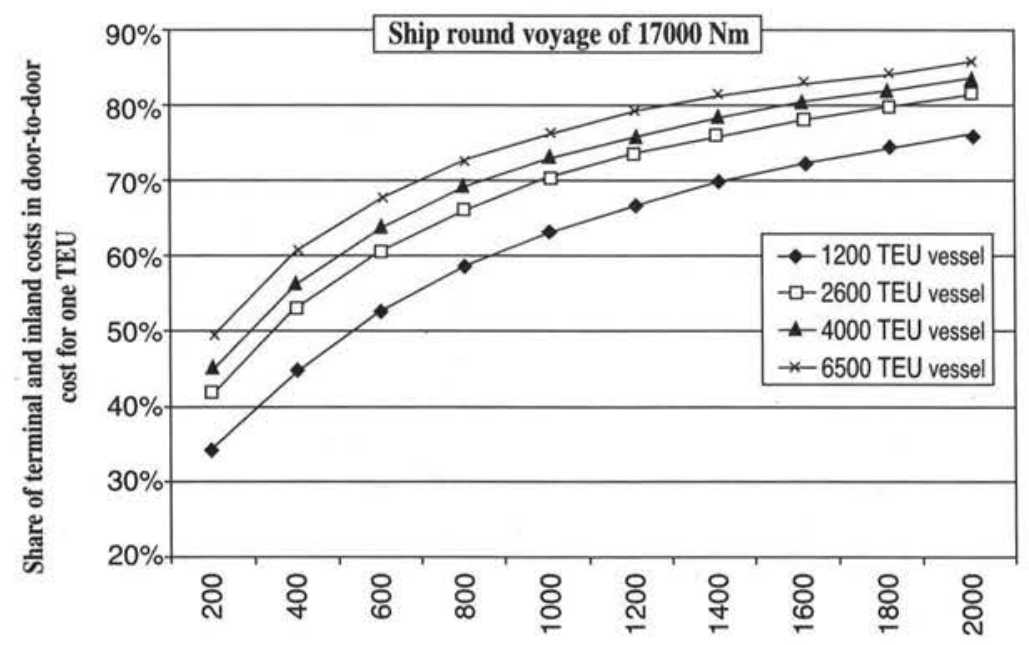

Average inland transport costs in US\$ per TEU (origin-port of loading and port of discharge-final destination, terminal costs ship not included)

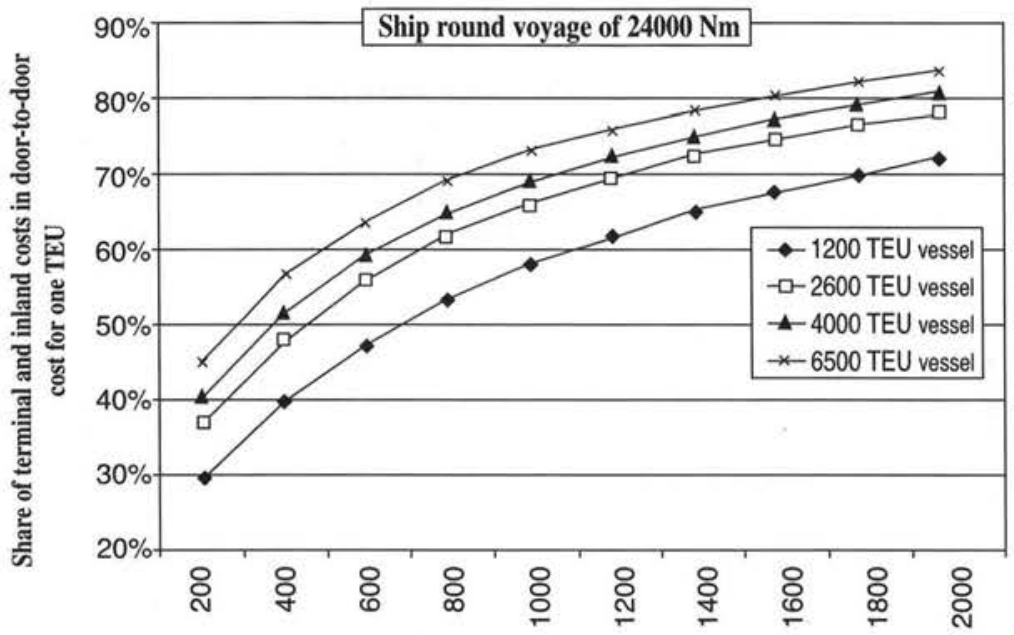

Average inland transport costs in US\$ per TEU (origin-port of loading and port of discharge-final destination, terminal costs ship not included)

Figure 1 clearly demonstrates that scale increases in vessel size shift the door-todoor cost burden from sea to land. The difference between a $1600 \mathrm{TEU}$ vessel and a 6500 TEU vessel in some cases exceeds $15 \%$. Even in the case of very long loops and low inland transport distances/costs the landside operations still account for at least $30 \%$ of total door-to-door cost. At the other extreme with inland transport costs of 
more than $\$ 1600$, the landside costs incurred represent 80 to $90 \%$ of total costs.

The shift of balance from vessel costs to landside costs is enhanced by transport price evolutions. Overcapacity keeps a limit on ocean pricing, while inland pricing is much more cost-driven. As such, cost increases in inland moves tend to pass through to price levels more easily compared to ocean moves, thereby increasing the absolute difference between both items. A factor often disregarded in this respect is the need to streamline and synchronize the configuration of shipping networks and inland networks.

\section{NETWORK CONFIGURATION}

Bundling is one of the key driving forces of container network dynamics. Figure 2 depicts three types of complex bundling networks that can be used as an alternative to direct point-to-point container services (Kreutzberger \& Bontekoning, 1998). In liner shipping, rail transport and inland shipping these types are often combined to form multi-layer networks. The advantages of complex bundling are higher load factors and or the use of larger transport units in terms of TEU capacity and or higher frequencies and or more destinations served. Container service operators have to make a trade-off between frequency and volume on the trunk lines: smaller unit capacities allow to meet the shippers' demand for high frequencies and lower transit times, while larger units will allow operators to benefit from economies of modal size. The main disadvantages of complex bundling networks are the need for extra container handling at intermediate terminals, longer transport distances and a higher dependency on service quality. These elements incur additional costs and as such could counterbalance the cost advantages linked to higher load factors or the use of larger unit capacities.

Figure 2. Basic models of network configuration in container transport

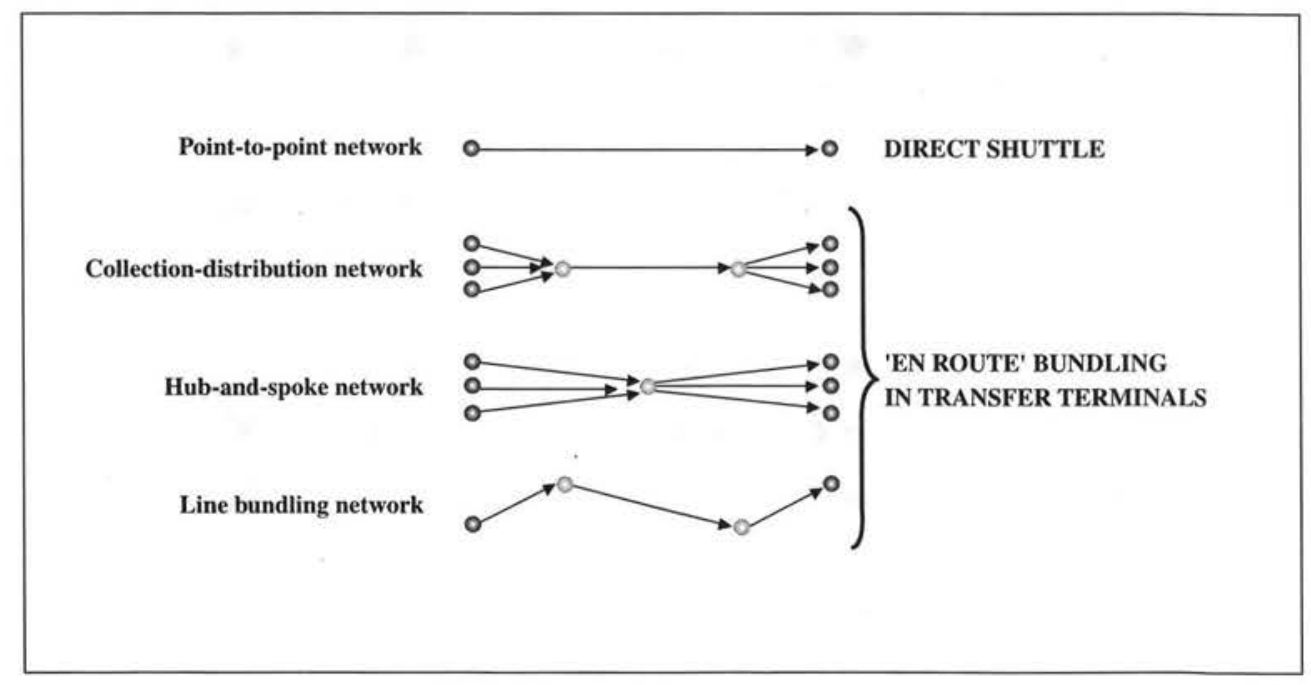


Figure 3. Basic combination models for liner services and hinterland services

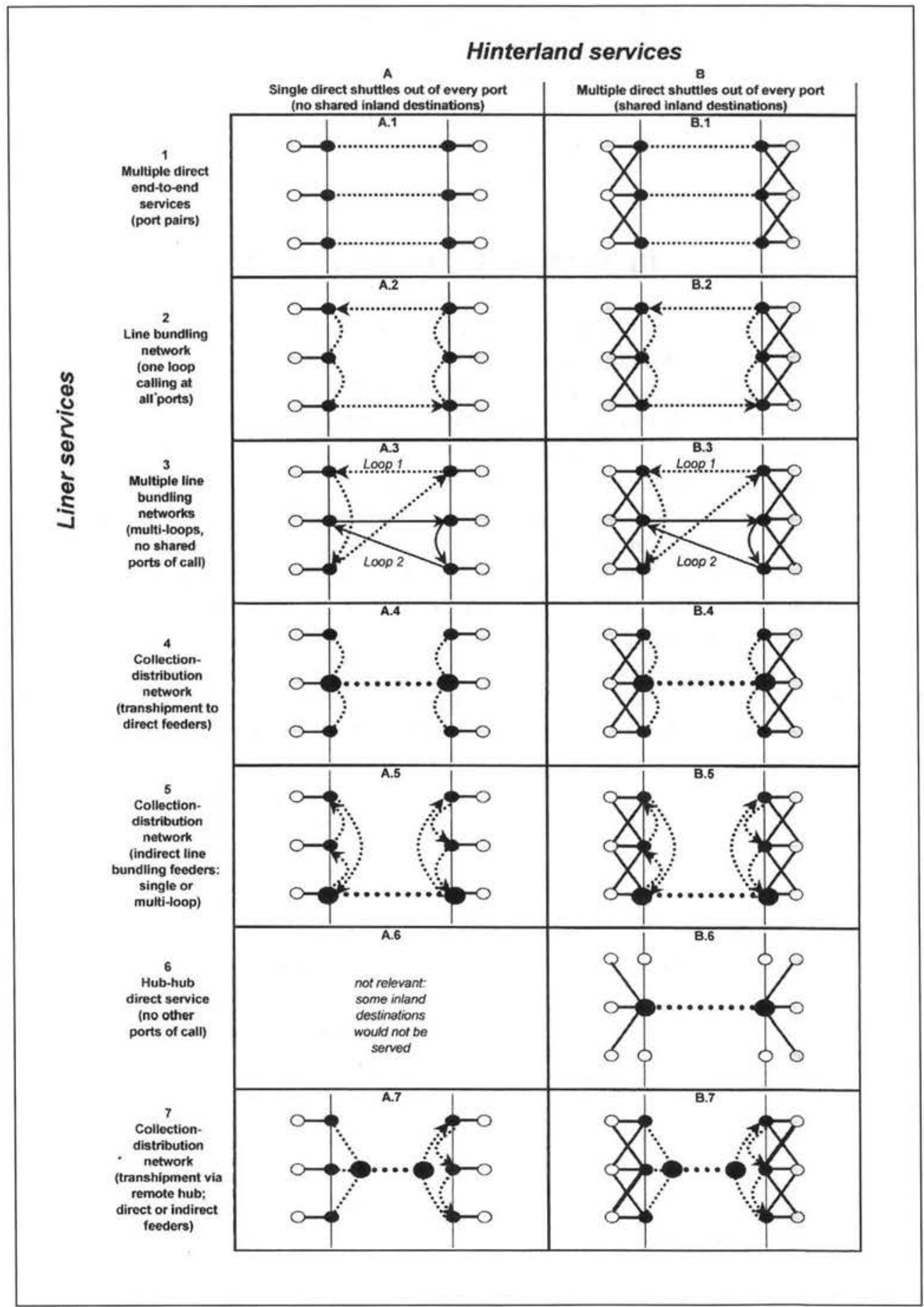

Source : author 
Figure 4. Basic combination models (continued)

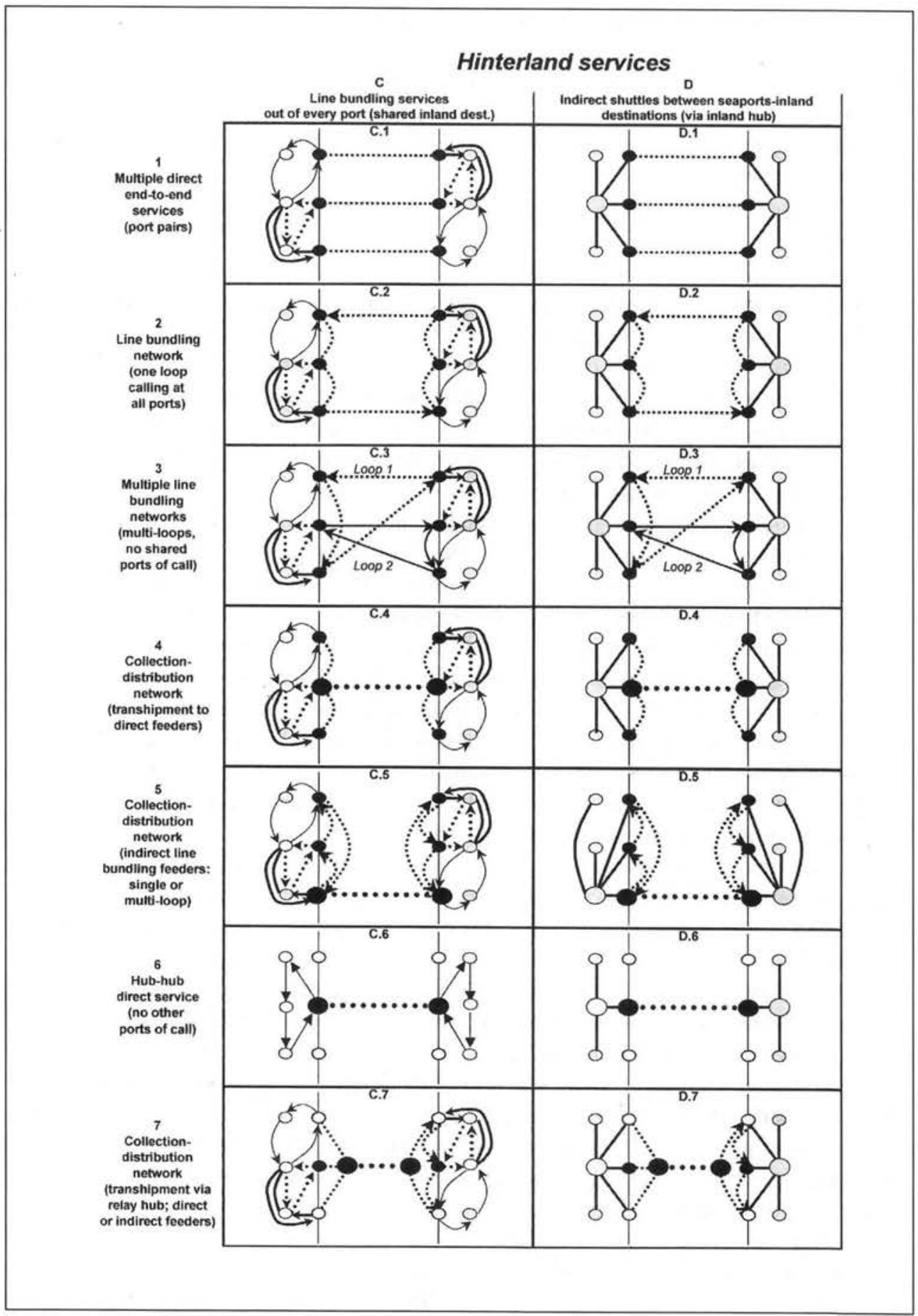

Source : author 
Figures 3 and 4 visualize 28 possible combinations of liner shipping networks and inland (intermodal) networks based on the network models depicted in figure 2 . The visualization is based on a simplified situation consisting of two port systems of three ports each and three hinterland regions per port system. Grey dots represent inland destinations (hinterland regions), while black dots are seaports. In reality, different combinations of the proposed basic models might occur.

From a carriers' perspective the optimal network combination will depend on many factors, including:

- The number, productivity, charges and terminal costs of seaports/inland terminals;

- The distribution of service demand;

- The number of inland destinations, the density of cargo flows to/from inland destinations and the existence of trade imbalances. The available cargo volumes will have an impact on the carriers' possibilities to deploy large vessels, train combinations or barge units without lowering frequency of service;

- Distances and related mode operating costs between seaport systems, between seaports and inland destinations and between seaports of the same port system (including diversion distance from the main shipping lanes);

- Transit times: longer transit times incur additional time costs to transport modes (carrier focus) as well as to the cargo (shippers' interest).

Carriers primarily look at cost minimisation of their multimodal network operations, whereas shippers are more interested in cost minimisation of a set of logistics chains. As such, shippers' preferences are not only driven by transport and port costs, but also by costs linked to value added services in nodes as well as inventory costs. Carriers have to offer regular schedules with service characteristics that do not alter too frequently (Brooks, 2000). Shippers also show a keen interest in the performance of the whole transport chain in terms of reliability, availability and compatibility. Hence, inefficiencies at this level will generate indirect logistics costs (e.g. production losses caused by late deliveries).

Carriers and transport operators design the networks they find convenient to offer, but at the same time they have to provide the services their customers want in terms of frequency and direct accessibility. This tension between routing and demand is important.

The network planners may direct flows along paths that are optimal for the system, with the lowest cost for the entire network being achieved by indirect routing via hubs and the amalgamation of flows. However, the more efficient the network from the carrier's point of view, the less convenient that network could be for the shippers' needs. Shippers could resent the indirect routes, opening the possibilities for other shipping lines to fill gaps in the market. It is therefore clear the spatial development of liner shipping networks and inland networks largely depends on the balance of power between shippers and carriers.

Human behavioural aspects might impede carriers from achieving an optimal network configuration. Incorrect or incomplete information results in bounded rationality in carriers' network design, leading to sub-optimal decisions. Shippers 
sometimes impose bounded rational behaviour on transport operators, e.g. in case the shipper asks to call at a specific port or to use a specific land transport mode. Secondly, opportunistic behaviour of economic actors or informal commitments to individuals or companies might lead to non-cost minimizing decisions. Thirdly, carriers might stick to a specific network design as they assume that the mental efforts (inertia) and transactions costs linked to changes in network design will not outweigh the extra costs of the current non-optimal solution.

Shippers preferences and behavioural aspects are surely having an influence on network design by shipping lines and transport operators, but the exact measurement of these impacts remains a challenge that is not tackled in this paper.

The perspective in this paper is that of a rational carrier whose objective is to minimize network costs linked to its shipping and landside operations. This focus should be kept in mind while interpreting the results. For instance, some of the proposed combinations depicted in figures 3 and 4 are likely to be sub-optimal from a pure network cost perspective: it is not very likely that the B.4 option would be superior to A.4 at the level of total network costs nor that D. 4 would be more cost efficient than D.6, B.6 or A.4. But still a more elaborate network configuration could be extremely valuable in meeting shippers' requirements in terms of market coverage, frequency or the availability of alternative ways to reach the hinterland destination. D. 4 and B.4 might not be very cost competitive at first glance, but at least they offer the possibility to direct cargo flows in various ways (more options available to shippers) and could allow carriers to optimise the use of their rolling equipment.

\section{ISSUES LINER SERVICE NETWORK DESIGN}

\section{IV.1. The emergence of new liner services}

Increased cargo availability has triggered changes in vessel size, liner service schedules and in the structure of liner shipping. Carriers and alliances have reshaped their liner shipping networks in the last two decades through the introduction of new types of end-to-end services, round-the-world services and pendulum services, especially on the main east-west trade lanes. Recently, the round-the-world service concept has been abandoned by carriers such as Evergreen, mainly because of the limits of the Panama Canal in terms of vessel size. Pendulum services rely on hub ports that act as turntables between liner services of two different trades and that are served by post-panamax vessels. This kind of liner service design has become popular on high-volume international trade routes such as the trade Europe-Far East- US West coast.

As a result the last decade has seen the emergence of a new breed of load centres along the east-west shipping lanes. New load centres in Asia, Latin America, the Middle East and the Mediterranean emerged at unlikely places far away from the immediate hinterland that historically guided port selection. These sites have been selected to serve continents and for transhipping at the crossing points of trade lanes. They rely heavily sometimes completely on traffic flows that are distantly generated 
by the interaction of widely separated places and stimulated by the port's en route location or intermediacy. Elsewhere, in particular in Northern Europe and North America, load centres are mainly functioning as gateways between deepsea liner shipping networks and extensive intermodal hinterland networks.

\section{IV.2. Maritime hub-feeder networks versus direct port calls}

Much literature has addressed the issue of the hub-feeder system versus direct port calls at continental ports. Some have suggested that the most efficient east/west pattern is the equatorial round-the-world, following the beltway of the world (cf. Ashar 2002 and De Monie, 1997). This service pattern focuses on a hub and spokes system of ports that allows shipping lines to provide a global grid of east/west, north/south and regional services. The large ships on the east/west routes will call mainly at transhipment hubs where containers will be shifted to multi-layered feeder subsystems serving north/south, diagonal and regional routes. Some boxes in such a system would undergo as many as four transhipments before reaching the final port of discharge. Liner service model 7 in figures 3 and 4 can be considered as a single-layer example of this service pattern.

Alternatively, models 4 and 5 are forms of hub-feeder systems built around hubs with an important cargo base in the local and distant hinterland.

Much of the discussion on the hub port system (and consequently on regional container distribution) has focused on the large mainline vessels. Less attention has been paid to feeder vessels and to the hinterland transport modes. Part of the problem is that some ports, particularly those which serve as direct port of call, or even cater for some transhipment traffic, feel that serving feeder vessels means a loss of status. Carriers have some feeder options available. Waals \& Wijnolst (2001) identify two main feeder systems: direct feeders between hub and feeder port (see model 4 in figures 3 and 4) and indirect feeders via line-bundling loops including more than one feeder port (model 5).

The first strategy has the lowest transit time but typically requires more feeders and smaller feeder vessels. Alternatively, indirect feeders benefit from economies of feeder vessel size, but incur longer distances and longer transit times.

The carrier's choice between one or more direct calls at mainland load centres with the mother vessel or an indirect call via a feeder vessel is determined by factors such as the diversion distance, draft conditions, the volumes of containers involved, the possibility to combine transhipment activities with a strong cargo-generating power of the port's regional hinterland, the related costs, port productivity and the strength of the individual carrier in the markets served (see e.g. Zohil \& Prijon, 1999, Notteboom, 2000). When point-to-point markets cannot support direct service in the container trade, shipping lines need to make decisions about transhipment locations. A wide range of appropriate tools is available to select an optimal transhipment location (see e.g. Fleming, 2000 and Waals \& Wijnolst, 2001). Hub-and-spoke networks would allow considerable economies of scale of equipment, but the cost efficiency of larger ships might be not sufficient to offset the extra feeder costs and container lift charges involved. Baird (2001) has demonstrated that the insertion of a 
remote hub in the United Kingdom in combination with onward feeders to the European mainland by means of large feeder units (model 7 in figures 3 and 4) constitutes a cost efficient alternative (i.e. at the level of operating and capital costs) to the system of multiple direct calls to north European load centres.

The attractiveness of the sea-sea hub-and-spoke network to a carrier also partly depends on the actor who will bear the transhipment costs. In the current market environment shippers typically bear these costs via extra THC or terminal handling charges (Brooks, 2000, Dynamar, 2003). This aspect in the balance of power between shippers and carriers increases the cost advantages of the hubbing option from a carrier's perspective, but may render a hub-and-spoke configuration uncompetitive from a shipper's perspective.

A pattern with the biggest ships possible on high-speed operations between a reduced number of hubs could be interesting from a pure liner network perspective, but it has not occurred in practice - at least not in north Europe. The reality of deepsea operations is that even the largest ships operate on multi-port itineraries and distribute cargo quite widely over trading hinterlands. Alliances and consolidation have created multi-string networks on the major trade routes and both shippers and liners are used to it. The multi-loop system of the alliances seems to offer a higher sailing frequency than the single loop-single carrier system. However, this is sometimes misleading: there might be one departure per day out of European load centres to e.g. the Far East, but in many cases these separate loops each call at a different set of ports in northeast Asia, China, southeast Asia and the Indian subcontinent.

In referring to the Asian hub/feeder restructuring, Robinson (1998) argues that a system of hub ports as main articulation points between mainline and feeder nets is being replaced by a hierarchical set of networks reflecting differing cost/efficiency levels in the market. High-order service networks will have fewer ports of call and bigger vessels than lower order networks. Increasing volumes as such can lead to an increasing segmentation in liner service networks and a hierarchy in hubs.

Recent developments in the liner shipping industry have revealed the weaknesses of pure hub-and-spoke systems versus multi-port itineraries. The hub-feeder structuring in the liner shipping business took place in an era of strong growth in cargo volumes. The inflexibility of this kind of system comes to the foreground when growth slows down. Decisions to cut costs by concentrating all cargo on only few loops negatively affect carrier operations. Only a limited number of carriers operate enough services to reduce capacity by taking a loop out of the market. This lack of flexibility also partly explains why carriers have decided not to introduce units of 10,000 TEU. A system of more loops with smaller vessels is regarded by many as the answer to cope with a market characterised by modest growth rates. This approach bears less risk and could therefore eventually turn out to be a cheaper option than running very large vessels on only few loops. Carriers are in the process of reviewing their strategy with respect to liner shipping networks, and this could very well introduce a tendency towards less transhipment and more direct port of calls (even for the bigger vessels). Gilman (1999) rightly stated that the networks operated by large vessels continue to be based on end-to-end services. Hub-and-spoke systems are just a part of the overall scene. 


\section{IV.3. The number of port calls per round trip}

When designing a liner service, carriers are considering primarily the market to be served. There are three key decisions for service planners to make: the service frequency (including the fixed day of the week port call), the number of port calls and the size of the ships used. Carriers will try to have at least a weekly service. The optimal vessel size depends on cargo availability, shippers' needs for transit time or other service elements and the choices made with respect to the other two key variables. As economies of vessel size are more significant on longer routes, the biggest vessels are deployed on the longest routes.

Limiting the number of port calls will shorten round trip times and increase the number of round trips per year, thereby maximizing revenue and minimizing the number of vessels required for that specific liner service'. The example in table 1 is based on the cost model introduced earlier in this paper. It is demonstrated that if a carrier would lower the number of calls from 14 (e.g. 7 on each side of the ocean) to just two, he could reduce ship costs per TEU. This observation is a combined result of several effects: (a) lower total port time and port charges on the round voyage, (b) a smaller number of ships needed to run a weekly service and (c) a smaller total round voyage length in nautical miles as diversion distances to additional ports of call are avoided.

Table 1. Relationship between vessel costs and the number of port calls

\begin{tabular}{|c|c|c|c|c|c|c|}
\hline Distance of round trip (nautical miles) ( $)$ & 17000 & 17400 & 17800 & 18200 & 18600 & 19400 \\
\hline Vessel size & 6500 & 6500 & 6500 & 6500 & 6500 & 6500 \\
\hline Average utilization slot capacity & $75 \%$ & $75 \%$ & $75 \%$ & $75 \%$ & $75 \%$ & $75 \%$ \\
\hline Total number of ports of call on round trip & 2 & 4 & 6 & 8 & 10 & 14 \\
\hline Number of TEU handled (loaded/discharged) per call & 9750 & 4875 & 3250 & 2438 & 1950 & 1393 \\
\hline Port time per call (days) (") & 3.2 & 1.7 & 1.2 & 1.0 & 0.8 & 0.7 \\
\hline Total port time on round trip (days) & 6.3 & 6.8 & 7.3 & 7.8 & 8.3 & 9.3 \\
\hline Total voyage time on round trip (days) & 38.5 & 39.8 & 41.0 & 42.3 & 43.5 & 46.0 \\
\hline Number of ships needed for weekly service & 5.5 & 5.7 & 5.9 & 6.0 & 6.2 & 6.6 \\
\hline TEU transported on service per year (weekly service) & 508393 & 508393 & 508393 & 508393 & 508393 & 508393 \\
\hline Traffic per port of call (TEU) generated by loop & 254196 & 127098 & 84732 & 63549 & 50839 & 36314 \\
\hline \multicolumn{7}{|l|}{ Ship costs per TEU transported( $\left(^{* * *}\right)$} \\
\hline Vessel operating costs $(\$)$ & 38 & 39 & 40 & 41 & 42 & 45 \\
\hline Vessel capital costs $(\$)$ & 113 & 116 & 120 & 124 & 127 & 135 \\
\hline Vessel bunker cost $(\$)$ & 51 & 52 & 53 & 54 & 56 & 58 \\
\hline Port charges (\$) (excluding cargo handling) ( & 9 & 18 & 26 & 35 & 44 & 62 \\
\hline Total ship costs per TEU transported (\$) & 210 & 225 & 240 & 254 & 269 & 299 \\
\hline Index $(2$ Ports of call $=100)$ & 100 & 107 & 114 & 121 & 128 & 143 \\
\hline
\end{tabular}

( ) It is assumed that the insertion of an extra port of call generates an additional diversion distance of $200 \mathrm{~nm}$ on an average

(") Based on 4 cranes per vessel, crane productivity of 35 TEU/crane/hour and 6 hours of nonproductive port time (berthing time+idle time terminal)

(**) Only vessel costs, so administative costs, container costs, inland transport and terminal handling costs are not included

( $\left.{ }^{* * *}\right)$ Port charges per TEU increase with the number of port call, as all containers call at the port even if the port is not the discharging point 
An empirical study of the US port system revealed that services at the West Coast have become concentrated in one-call strings, whereas at the East Coast carriers opt for three to four ports of call per loop. Carriers would concentrate their calls more along the West Coast than along the East Coast as average vessel size on the transPacific route is bigger (Lago et al, 2001). In Europe the situation is more complex. The Western Mediterranean has become a complicated blend of dedicated feeders, common-carrier feeders, interlining and local services offering transhipment or slotcharter space. The hub and spoke networks (and related feeder connections) in northern Europe have not developed to the level at which some observers have predicted. Transhipment volumes in North Europe do not exceed $40 \%$ of any port's throughput. Only Hamburg has emerged as a major feeder hub for the Baltic States and Scandinavia. Most mainline operators running services to/from the continent stick to line bundling itineraries with calls scheduled in each of the main markets, i.e. three to five regional load centres per loop with partly overlapping hinterlands. Carriers still choose for multiporting to benefit the most from complementary market elements in the individual load centres. The number of port calls is however limited to maximum five in order to benefit the most from potential economies of scale in sea and land transportation. Instead of having a system of multi-layer hub-feeder networks, carriers - at least in north Europe - stick to overlapping end-to-end, multi port of call service loops.

Figure 5. Relationship between vessel costs, vessel size and number of ports

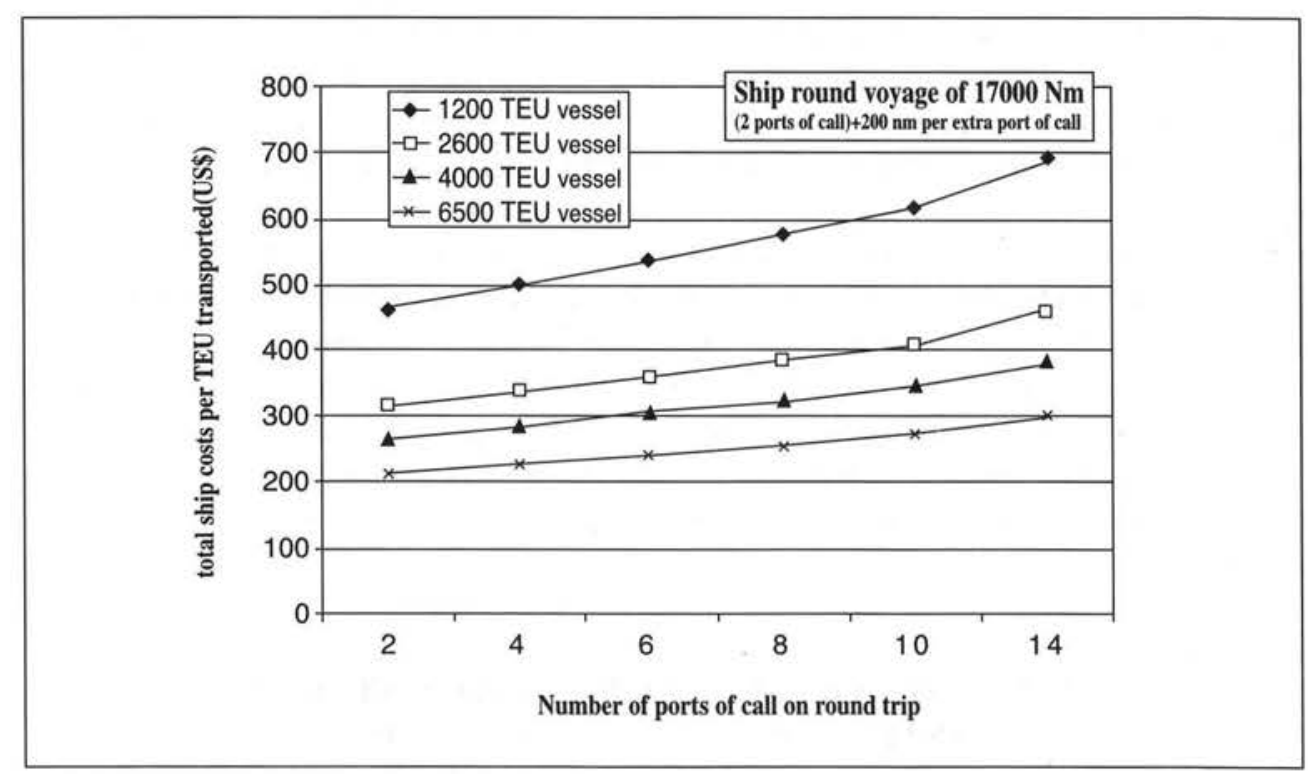

' There are of course other ways to reduce roundtrip times. For instance, Bendall \& Stent (1999) have referred to speed as a way to reduce roundtrip time. Increasing vessel speed incurs higher capital and bunker costs. These additional costs are not necessarily counterbalanced by savings in time costs. 
One of the reasons for this observation is that scale economies in the ship at sea are not totally lost by multi-port calling. In the example of figure 5, a 6500 TEU vessel that calls at 14 ports per loop has lower ship costs per TEU than a 2600 TEU unit servicing only two ports. The absolute cost advantages achieved by reducing the number of ports of call are more elevated in case of smaller vessels. In relative terms, the cost savings are almost the same for all vessel sizes. In figure 5 relative reductions in vessel costs per TEU between 14 and 2 ports of call range from $43 \%$ to $50 \%$ depending on vessel size.

Some factors have not been included in the cost model. There exist some factors that positively affect the choice for a limited number of ports per round trip. First, the bargaining power of a carrier with respect to terminal costs and port charges is expected to be higher if the carrier generates 250,000 TEU per loop per year in a port (on the basis of 2 ports of call in table 1) compared to 'only' 40,000 TEU (14 ports of call). This could be an additional incentive to limit the number of calls per loop. Second, adding a port of call to a string generates additional costs for more complicated vessel stowage and rehandles. Third, it might be possible to generate considerable economies of scale in hinterland transportation by concentrating a lot of cargo in only few ports of call. This issue will be addressed in detail later in this paper.

Alternatively, a lot of factors favour the multi-porting concept. Some of these have been mentioned earlier. First, transport distances are getting longer when the number of ports of call is reduced. This leads to higher inland costs as long as these longer distances are not counterbalanced by economies of scale in hinterland transportation. Second, it might be possible to realize a higher vessel utilization rate by having more calls per loop. Hence, you would be able to get more direct access to local hinterlands. Carriers need cargo at any price to fill their ships: in search for demand the marketing department of a shipping line might argue to stop at more ports than economies of scale might suggest. The incentive to call at more ports will increase when the distances between the individual ports in the port system are bigger. Typically, the higher inter-port distances the lower the overlap in the individual ports' hinterlands. Moreover, the higher the bargaining power of shippers vis-à-vis carriers the more pressure for direct calls as this will shift the 'cargo follows ship' principle to the 'ship follows cargo' principle. The optimal liner schedule as such is not only function of carrier specific operational factors, but also of shippers' needs (for transit time and other service elements) and of shippers' willingness to pay for a better service.

\section{LINER SERVICE NETWORKS AND HINTERLAND (INTERMODAL) NETWORK DESIGN}

\section{V.1. General considerations}

The spatial and functional integration of liner shipping networks with hinterland networks proves to be essential for a carrier's competitiveness. The concentration of 
container flows in a limited number of ports of call combined with a growth in container volumes generate a disproportionate increase in distribution requirements both from the perspective of individual carriers as well as the ports as a whole. The immense pressure on the collection and distribution networks creates the conditions for large-scale intermodal initiatives in the area of sea-rail, sea-inland navigation and sea-sea and enhances the development of inland hubs.

A main problem facing intermodal operators and shipping lines is to provide an adequate answer to the shippers' demand for frequent inland services (in number of departures per week) and the operators' interest in attaining a high volume per haul in order to gain a reasonable profitability. Direct inland shuttle services (model A en B in figures 3 and 4) are the most economical form of inland operation, as there is no need for time-consuming and expensive 'en route' bundling in transfer terminals. If a carrier uses model $\mathrm{A}$ in hinterland distribution, each port of call will serve its direct hinterland, so there will be no shared inland destinations between the individual ports of call. Although this model might be interesting from a pure network cost perspective, it suffers from a lack of flexibility: (1) each inland destination is connected to only one seaport, so there are no alternatives available to shippers and carriers to direct cargo differently, (2) frequencies will be very low if the cargo availability is very low and (3) the model is not suited to tackle equipment and trade imbalances (i.e. direct effect of 1). Model B offers more flexibility, but the danger of having insufficient volumes to operate frequent direct services to all destinations is real. If container volumes are too low to allow direct shuttles on a frequent basis, carriers will have to rely on line bundling services towards the hinterland (model C) or indirect shuttle networks relying on inland load centres (model D). On the one hand, models $\mathrm{C}$ and $\mathrm{D}$ lead to longer distances and longer transit times in the hinterland network, creating extra operating costs for the intermodal equipment. In addition, model $\mathrm{D}$ involves time-consuming and cost-increasing extra container handling in inland hubs. On the other hand, it is expected that these extra costs will be partly or even completely counterbalanced by cost reductions on the trunk lines between seaports and inland load centres. Hence, extensive cargo concentration on a few trunk lines opens possibilities to economies of scale in inland shuttles (through the deployment of longer trains or larger inland barges) but even more likely to higher frequencies. Moreover, inland load centres enable to extend the transportation network inland far beyond the seaports, thus relieving some pressure of the collection and distribution networks in the vicinity of seaports.

A carrier who pursues economies of scale throughout the foreland-hinterland continuum has to be aware of possible negative side effects. First, extreme forms of cargo concentration in seaport and inland centres (e.g. model D.6) could decrease the efficiency of transport systems because shipments would significantly be delayed, although having low transport costs. Hence, the current development and expansion of intermodal transportation relies on the synchronization of different geographical scales. But when the synchronization level increases, the sea-land network as a whole becomes more instable (Rodrigue, 1999). For instance, if a segment in the container chain does not work efficiently in a highly synchronized environment than the whole chain will be affected. This leads to extra costs to find alternative routes. 
Second, shipping lines often use port equalisation systems to ensure that shippers are compensated for possible cost disadvantages linked to the bundling of cargo in just a few ports of call. The carriers will equalise charges for inland transport from points in the hinterland to a range of designated base ports which it serves (Gilman, 1997). With the severe pressure on ocean freight rates of recent years, the limited shipping revenue of major sea carriers makes it increasingly difficult to sustain the existing port equalisation systems. The increased danger of cost under-recovery on such inland moves calls for a restructuring in the absorption pricing systems and favours multi-port loops.

Third, it was mentioned earlier on that the price difference per TEU-km between inland transport and long-haul liner shipping ranges from a factor 5 to a factor 30 . A policy directed towards the internalisation of external costs as suggested by EU policy documents would widen the gap between sea and land transport costs (especially as regards the road haulage option). Such a policy would increase the share of inland costs in door-to-door costs per TEU while at the same time supporting a modal shift to rail and inland navigation. Eventually, this will also affect carriers' liner service design.

\section{V.2. Cost model results}

In this section the cost model is used to assess the sensitivity of the optimal configuration of a liner shipping network to changes in hinterland network design and vice versa. The cost model is applied to a selection of five cases in figures 3 and 4:

- Model A.1: direct port pair services using 2600 TEU vessels and linked to direct shuttles to captive inland destinations;

- Model A.2: a maritime line-bundling network using 6500 TEU vessels and combined with direct inland shuttles;

- Model A.3: multi-loop services (no overlapping ports of call and 2600 TEU vessels) combined with direct inland shuttles;

- Model B.2: a maritime line-bundling network using 6500 TEU vessels and combined with a set of direct inland shuttles to overlapping inland destinations;

- Model B.6: one hub port serves all inland destinations.

The hypothetical geographical situation of ports and inland centres/regions is depicted in figure 6 . The average distance between a seaport and destinations in its nearest hinterland region is $200 \mathrm{~km}$. The distance between two neighbouring ports in the ports system is set at $250 \mathrm{~nm}$ or $450 \mathrm{~km}$. Three distances between both port systems are considered: 2000,6000 and $12000 \mathrm{~nm}$. It is assumed that if a port serves more than one inland region the associated cargo is distributed evenly among the different inland destinations. The main input data for the cost model have been discussed earlier in this paper and are recapitulated in appendix. 
Figure 6. A hypothetical port system with inland destinations

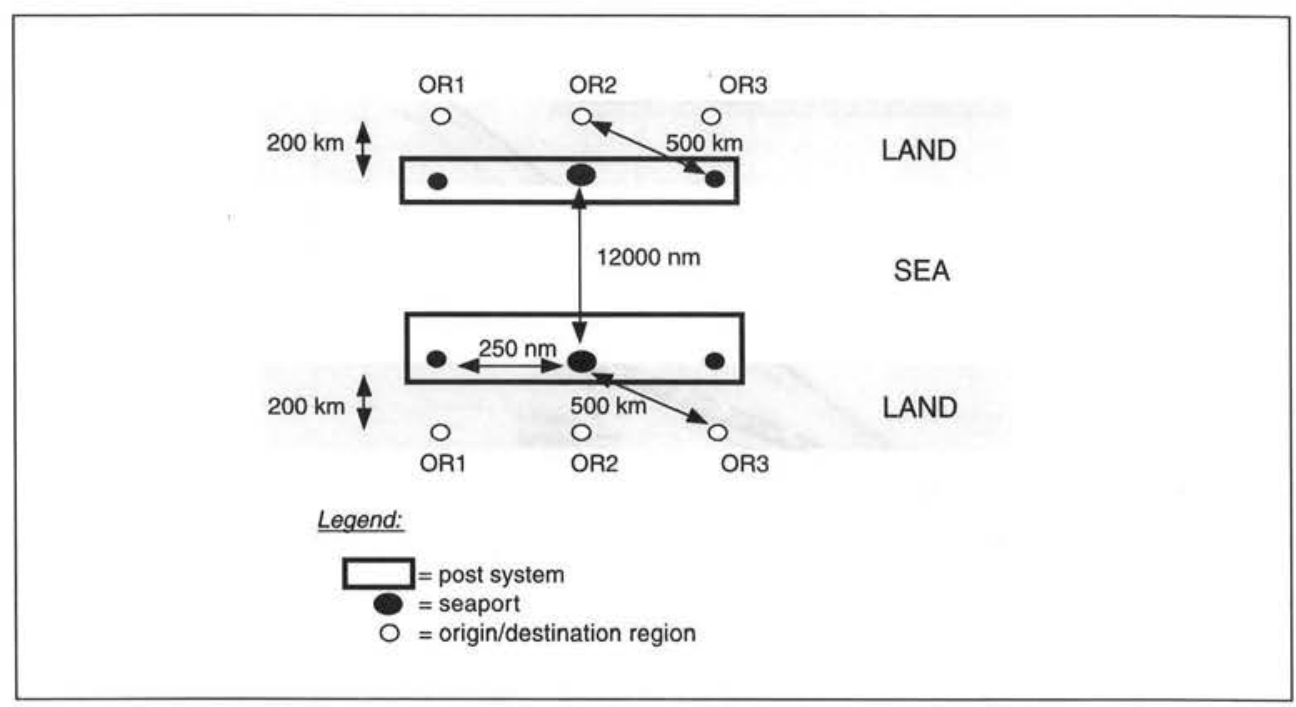

Table 2. Transit times in days

\begin{tabular}{lccccc}
\hline Total transit time & A.1 & A.2 & A.3 & B.2 & B.6 \\
\hline OR1-DR1 & 26.9 & 32.3 & 28.8 & 32.3 & 28.3 \\
\hline OR1-DR2 & & 30.6 & & 30.6 & 27.9 \\
\hline OR1-DR3 & & 28.9 & & 28.9 & 28.3 \\
\hline OR2-DR1 & 26.9 & 28.6 & & 30.6 & 27.9 \\
\hline OR2-DR2 & & 27.2 & 28.1 & 28.9 & 27.5 \\
\hline OR2-DR3 & 26.9 & 29.7 & 27.8 & 29.2 & 27.9 \\
\hline Average transit time (days) & 2600 & 6500 & 2600 & 6500 & 28.0 \\
\hline Vessel size & & & & 6500 \\
\hline
\end{tabular}

Notes : Dwell time at terminal of one day. Distances are based on figure 6. Average speed of inland transport mode is set at $30 \mathrm{~km} / \mathrm{h}$ (including loading and discharging time). Vessel speed is 22 knots.

Table 2 depicts the transit times linked to each of the alternatives. Transit times range from 26.1 to 32.3 days. The total transit times of options A.2 and B.2 can vary substantially. If the container's port of loading is the last port of call on the maritime line-bundling service and the port of discharge the first port of call than roundtrip time is minimized. The smallest transit time is achieved when model A. 3 is used.

It was stated earlier that the bundling of cargo on trunk lines between seaports and inland load centres normally leads to unit cost reductions as it opens possibilities to economies of scale in inland shuttles. In order to take into account possible cost savings through cargo bundling in a seaport, it was decided to add three cases to the five selected models. It concerns three variants of model B.6 that all incorporate the realisation of economies of scale in inland cargo bundling. 
Figure 7. Total door-to-door costs per TEU for a set of network models
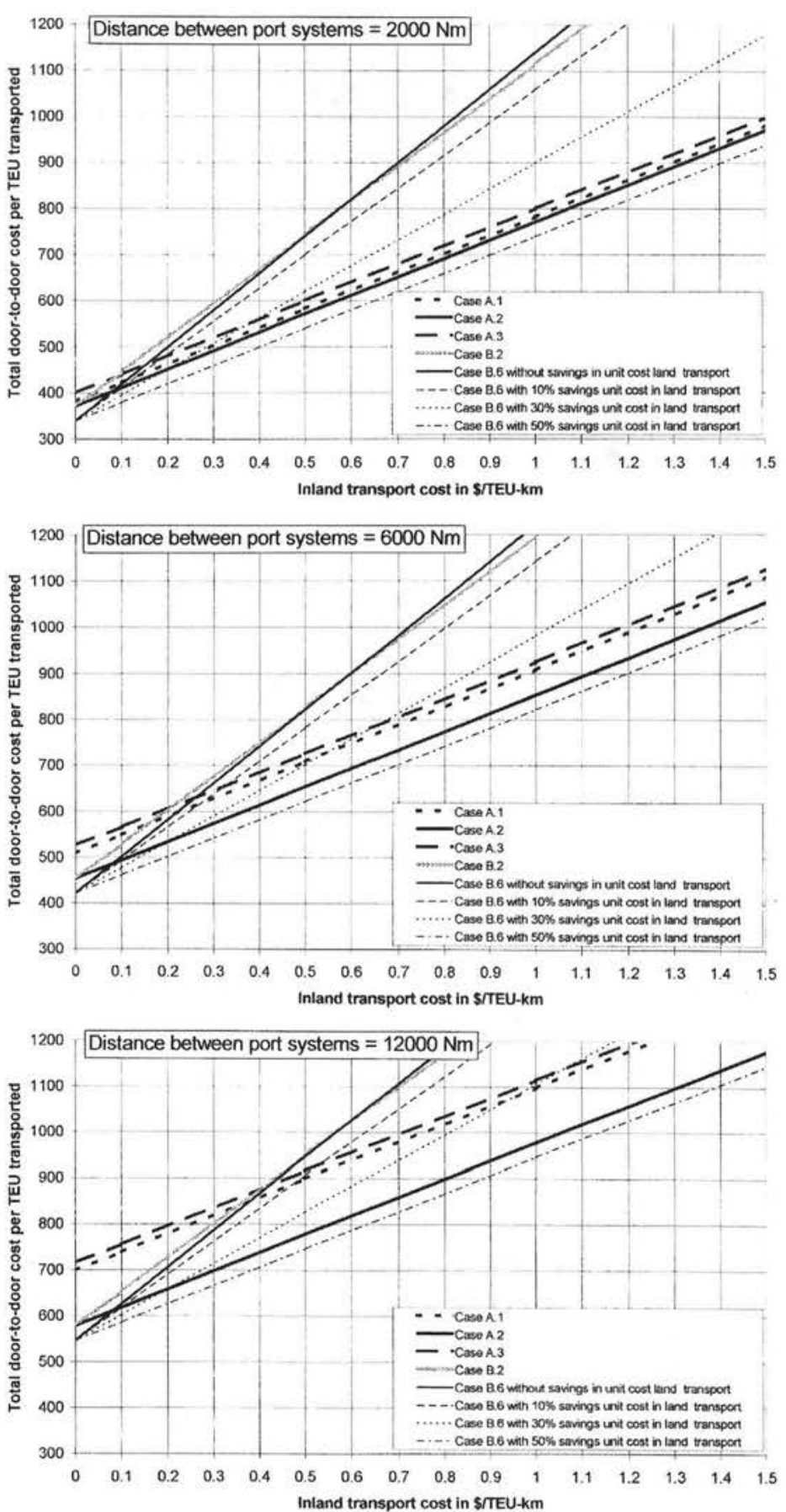
Figure 7 demonstrates that the B.6 model is the cheapest option from a network cost perspective only if the bundling of cargo goes hand in hand with considerable economies of scale and density in the related hinterland services network (i.e. economies of scale that lead to a 50 per cent reduction in the unit cost of inland transport). In case the large-scale bundling of cargo results in very limited or even in no economies of scale in hinterland transport, it is more cost efficient to opt for model A.2. The cost model data and assumptions demonstrate that model A.2 outperforms models A.1, A.3 and B.2 irrespective of unit costs in inland transport. Options A.1 and A.3 are more expensive as the related liner services use 2600 TEU vessels to guarantee the same sailing frequency as in model A.2.

Figure 8. Total door-to-door costs per TEU for a set of network models

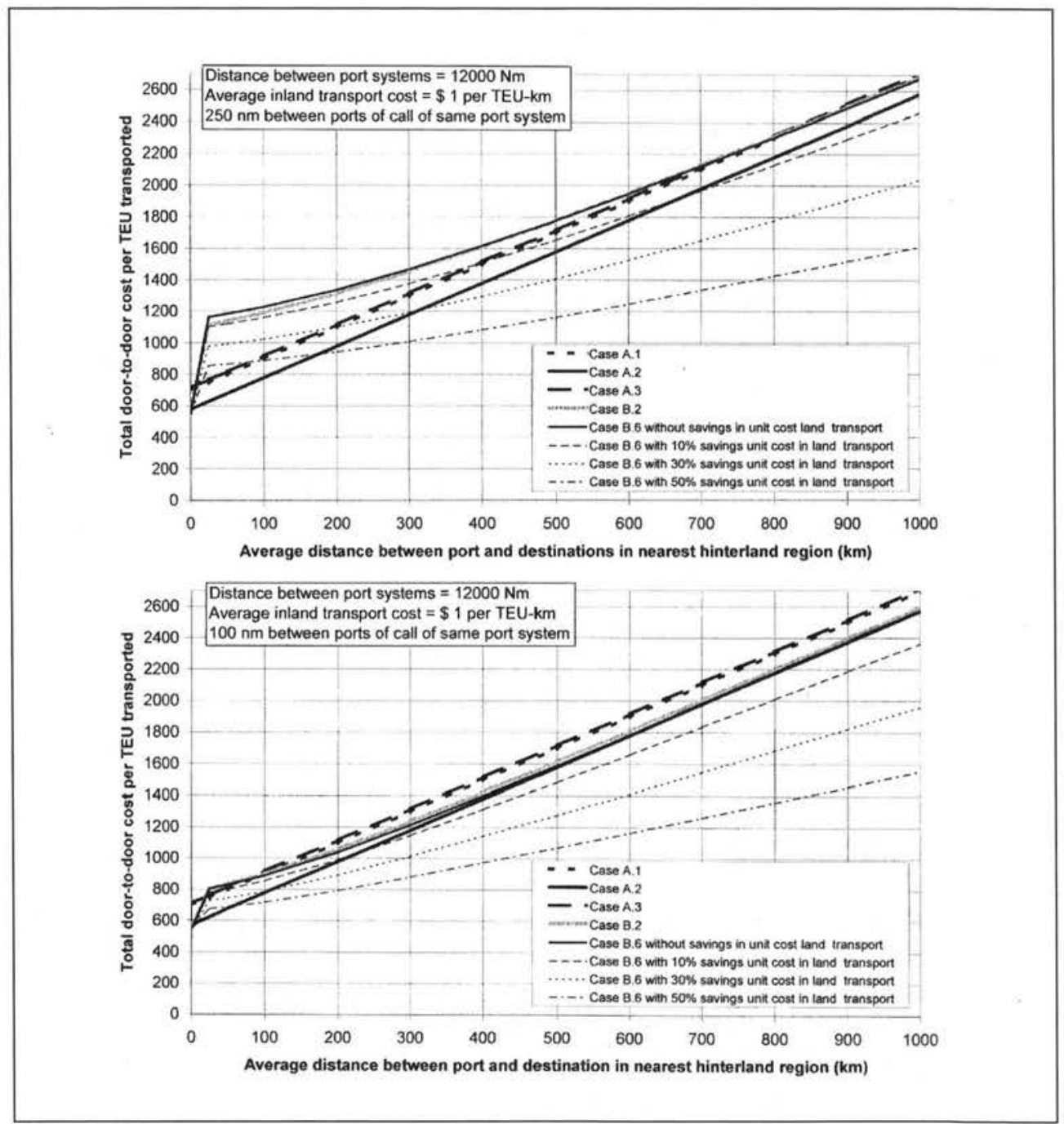

Source : author based on cost model output 
In figure 8 the average inland transport cost is fixed at \$1 per TEU-km whereas the average distance between a port and destinations in its nearest hinterland region is made variable. Longer inland distances make model B.6 more cost competitive, at least if the bundling of cargo in the hub port generates some economies of scale in inland transportation. The feasibility of model B.6 further increases if the average distances between neighbouring load centres in the port systems decline. This observation partly explains why carriers tend to opt for just one port of call per regional port group (where distances between neighbouring ports are typically below 200nm).

Even though the results are based on a hypothetical case, figures 7 and 8 clearly demonstrate the interdependence between liner networks and hinterland networks: extensive cargo concentration on only few nodes in the foreland-hinterland continuum only pays off if considerable economies of scale and density can be realised in the associated hinterland networks.

\section{CONCLUSIONS}

Carriers are well aware of the growing importance of landside operations in the door-to-door costs. Ship system costs have already been reduced considerably in the last decade and the potential cost savings in this area are getting smaller. The cost burden has now shifted to inland logistics as one of the most vital area still left to cut costs. Carriers have developed strategies to face the challenges in landside operations and to tackle inland logistics costs. These strategies are mainly focused on cost reductions, as carriers have little room to increase the income out of landside operations. In this context, much attention is directed to the configuration and synchronization of the services schedules in the foreland-hinterland continuum.

This paper has demonstrated that the design of liner shipping networks and hinterland networks are strongly intertwined and are affected by many factors. Carriers have been able in the past to limit ports of call partly as a result of advances in large-scale intermodal transport combined with absorption pricing systems. Load centres are only as competitive as the inland and relay links that connect to it. Further cargo bundling in the foreland-hinterland continuum towards even fewer ports and inland centres is only interesting from a cost perspective if considerable economies of scale and density can be realised in the associated hinterland networks. In liner shipping the limits to economies of scale and density have been reached. In the hinterland routing of containers by rail and barge, direct shuttles have been complemented by hub-based indirect shuttle networks.

The optimal network design is not only function of carrier-specific operational factors, but also of shippers' needs (for transit time and other service elements) and of shippers' willingness to pay for a better service. Carriers therefore should not develop a unilateral focus on cost reductions by means of economies of scale. The more cost efficient the network becomes from a carrier's perspective, the less convenient that network could be for the shippers' needs in terms of frequency and flexibility. Recent developments in liner shipping have revealed the weaknesses of pure hub-and-spoke 
networks versus multi-port itineraries. The future spatial development of liner schedules and inland service networks will largely depend on the balance of power between carriers and shippers.

\section{LIST OF REFERENCES}

ASHAR, A, 2002, Revolution now, Containerisation International, January 2002

BAIRD, A.J. and LINDSAY, A.J., 1996, Strategic choice in the Global Container Shipping Industry: a resource-based approach. IAME '96 Conference, International Association of Maritime Economists, Vancouver

BAIRD, A.J., 2001, A new economic evaluation of the hubport versus multiport strategy, Proceedings of the IAME 2001 conference, Hong Kong, 138166

BENDALL, H.B., STENT, A.F., 1999, Longhaul feeder services in an era of changing technology: an Asia-Pacific perspective, Maritime Policy and Management, 26(2), 145-159

BROOKS, M., 2000, Sea change in liner shipping: regulation and managerial decision-making in a global industry, Pergamon

CARIOU, P., 2001, Vertical integration within the logistic chain: does regulation play rational? The case for dedicated container terminals. Transporti Europei, 7 (17), 37-41

CULLINANE, K., KHANNA, M., SONG, D.-W., 1999, How big is beautiful: economies of scale and the optimal size of containership, Liner shipping: what's next?, Proceedings of the 1999 IAME conference, Halifax, 108-140

DE MONIE, G., 1997, The global economy, very large containerships and the funding of mega hubs, Port Finance Conference, London, June 26-27, 1997

DREWRY SHIPPING CONSULTANTS, 2001, Post-Panamax Containerships The Next Generation, London

DYNAMAR (2003), Terminal Handling Charges: a bone of contention, Dynamar, Alkmaar, 57.

FLEMING, K., 2000, A geographical perspective on the transhipment function, International Journal of Maritime Economics, 2 (3)

GILMAN, S., 1997, Multimodal rate making and the structure of container networks. Essays in memory of Professor B.N. Metaxas, University of Piraeus, 327-335

GILMAN, S., 1999, The size economies and network efficiency of large containerships, International Journal of Maritime Economics, 1(1)

GRAHAM, M.G., 1998, Stability and competition in intermodal container shipping: finding a balance, Maritime Policy and Management, 25(2), 129-147 
HEAVER, T., 2002, The evolving roles of shipping lines in international logistics, International Journal of Maritime Economics, 4, 210-230

KONINGS, R., 1993, De rol van de zeerederij in het achterlandvervoer van containers, Tijdschrift Vervoerswetenschap, 29(3), 225-233

KREUTZBERGER, E., BONTEKONING, Y., 1998, Could new-generation terminals improve the competitiveness of intermodal transport? New-generation rail terminal evaluation, 8th World Conference of Transport Research, Antwerp

LAGO, A., MALCHOW, M., KANAFANI, A., 2001, An analysis of carriers' schedules and the impact on port selection, Proceedings of the IAME 2001 conference, Hong Kong, 123-137

LIM, S.-M., 1998, Economies of scale in container shipping, Maritime Policy and Management, 25(4), 361-373

NOTTEBOOM, T., 2000, The peripheral port challenge in container port systems, IAME-conference 'Maritime industry in the new millennium: the interaction of theory and practice', International Association of Maritime Economists, Naples (CD-Rom).

NOTTEBOOM, T., 2001, Spatial and functional integration of container port systems and hinterland networks in Europe. ECMT (ed.), Land access to seaports, Economic Research Centre ECMT-OECD, Paris, 5-55

ROBINSON, R., 1998, Asian hub/feeder nets: the dynamics of restructuring, Maritime Policy and Management, 25(1), 21-40

RODRIGUE, J.-P., 1999, Globalization and the synchronization of transport terminals. Journal of Transport Geography, 7, 255-261

SLACK, B., COMTOIS, C. and SLETMO, G., 1996, Shipping lines as agents of change in the port industry. Maritime Policy and Management, 23(3), 289-300

STOPFORD, M., 1999, Maritime Economics, second edition, Routledge, London

WAALS, F., WIJNOLST, N., 2001, Malacca-max: container shipping network economy, Proceedings of the IAME 2001 conference, Hong Kong, 191-207

ZOHIL, J., PRIJON, M., 1999, The MED rule: the interdependence of container throughput and transhipment volumes in the Mediterranean ports. Maritime Policy and Management, 26, 175-193

\section{APPENDIX}

\section{The components of the cost model}

\section{Ship costs}

Vessel operating costs, vessel capital costs, bunker costs and port charges (excluding cargo handling) 
Container costs

Cost of supplying containers, container repair and maintenance costs, reefer costs

Administrative costs

Cargo handling and onward transportation

Terminal handling costs, inland transport costs (pre-haul to port of loading and end-haul from port of discharge), inter-zone repositioning and cargo claims

\section{Some general assumptions for all vessel sizes}

Available slots: $57 \%$ FEU-slots, $37 \%$ TEU-slots and $6 \%$ reefer slots Vessel speed: 22 knots

Vessel utilization: $70 \%$ on the outward voyage, $80 \%$ on the return voyage Crane density: 1200 TEU \& 2600 TEU $=2,4000$ TEU $=3$ and 6500 TEU $=4$ Crane productivity at the terminals: 35 TEU per crane-hour for all vessels or 20 to 25 moves per crane-hour depending on the 20'/40' ratio and twin lift capabilities of the cranes. 